\title{
The use of stable isotopes and mass spectrometry in studying lipid metabolism
}

\author{
BY MICHEL BEYLOT \\ INSERM U. 197, Faculté de Médecine Alexis Carrel, rue G. Paradin, \\ 69372 Lyon Cédex 08, France
}

Lipids have several important roles in the organism. First, they act as energetic substrates. The triacylglycerols (TAG) stored in adipose tissue represent the main part of body energy stores. Lipid oxidation contributes as much as $50 \%$ of energy needs in the postabsorptive state and becomes predominant in prolonged fasting and exercise (Cahill, 1976). Second, long-chain polyunsaturated fatty acids are precursors of important bioactive molecules such as prostaglandins or leukotrienes. Last, phospholipids and complex lipids incorporated in membranes play a fundamental role in the structural organization of the cell. Stable isotopes and mass spectrometry (MS) are useful tools to study these various aspects of lipid metabolism. The present review will focus on lipids as energetic substrates. The reader interested in other aspects is referred to other excellent reviews (Gordon, 1980; Murphy, 1993).

\section{OVERVIEW OF LIPID TRANSPORT IN PLASMA}

Lipids are an efficient way to store energy. However, their poor solubility in the aqueous phase makes their transport in plasma throughout the body difficult. Organisms have had to develop mechanisms allowing their transport from lipid-storing tissues to lipidutilizing tissues and from points of synthesis and/or assembly or of intestinal absorption to storage depots. One system is the transport of non-esterified fatty acids (FFA) bound to plasma albumin. It allows the delivery of fatty acids liberated through the breakdown of TAG stored in adipose tissue to tissues for oxidative or non-oxidative purposes. The transport of TAG, phospholipids and cholesterol, either synthesized by the organism or coming from the diet, involves the more complicated lipoprotein system (chylomicrons; very-low- (VLDL), intermediate- (IDL), low- (LDL) and high- (HDL)-density lipoproteins). Most of these aspects of lipid metabolism and of their hormonal and nutritional regulation can be explored in vivo in humans using stable isotopes and MS techniques.

\section{NON-ESTERIFIED FATTY ACID METABOLISM}

\section{Lipolysis}

The appearance rate of FFA in plasma can be determined from the dilution of a continuously-infused labelled fatty acid. Since it would be difficult to trace each of the individual plasma FFA, usually only labelled palmitate (Wolfe et al. 1980; Bougnères \& Bier, 1982) or oleate (Miles et al. 1987) are infused. The basis of this choice is that each of these fatty acids represents an appreciable percentage of total FFA and, on a whole-body basis, their metabolism is representative of that of other fatty acids (Hagenfeldt, 1975; Spitzer, 1975). Exceptions are short- and medium-chain fatty acids which are soluble in aqueous phase and arachidonic acid whose metabolism is different; 

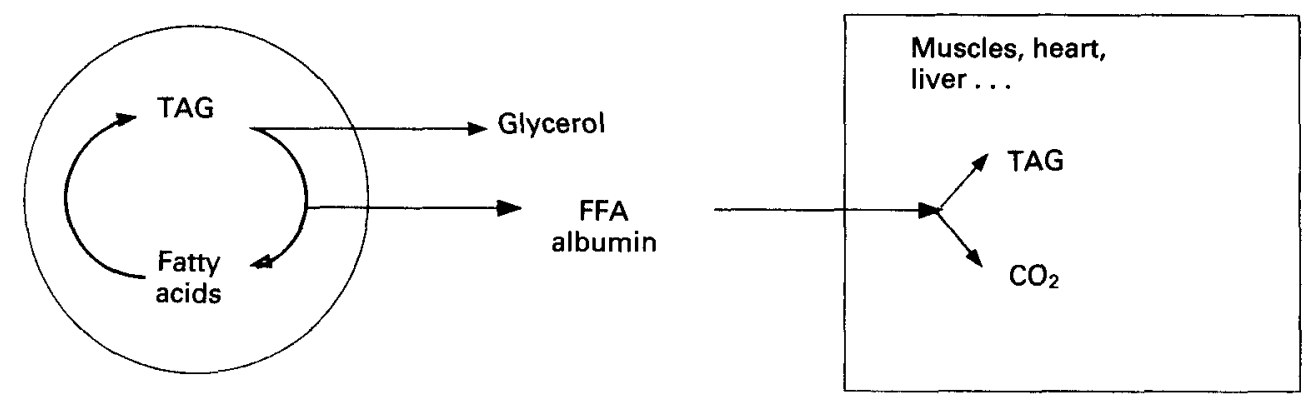

Fig. 1. Schematic representation of intracellular and extracellular recycling. Intracellular recycling is the direct re-esterification of fatty acids within tissues; it can be estimated by the simultaneous measurement of glycerol and plasma non-esterified fatty acid (FFA) turnover rate. Extracellular recycling is the re-esterification of plasma FFA taken up by tissue; it can be estimated by comparing plasma FFA turnover and oxidation rates. TAG, triacylglycerol.

quantitatively these fatty acids are usually minor. Labelled palmitate is the usual choice since it is the cheapest tracer and its separation from the other fatty acids by GLC is easy. The calculation of the turnover rate of total plasma FFA from that of palmitate or oleate requires the measure of the relative contribution of palmitate or oleate to total FFA concentration. This can be obtained easily by the addition of, for example, deuterated standards before the processing of plasma samples (Bougnères \& Bier, 1982). It is necessary to bind the tracer to albumin before infusion. Thereafter, the high fractional turnover rate of FFA usually results in the achievement of isotopic steady-state in 40-50 min, even without a priming dose. During metabolic steady-state the Steele equation for steady-state gives accurate results (Miles et al. 1987). In the absence of steady-state, the non-steady-state equation of Steele can be employed, with plasma volume as the volume of distribution either using raw experimental points or after curve-fitting (Wolfe et al. 1987a). However, when deviations from steady-state are slight, use of steady-state equations for each experimental point can give adequate results (Miles et al. 1987).

Experiments in humans or animals are usually performed with intravenous infusion of the tracer and sampling of mixed arterialized blood (V-A mode). However, experimenters should keep in mind that somehow different results are obtained when the infusion sampling mode is reversed (A-V mode) (Goodenough \& Wolfe, 1983). Which mode is the more appropriate is still debated (Goodenough \& Wolfe, 1983; Miles et al. 1987; Sacca et al. 1992), but theoretical considerations support the A-V mode. Infusing a tracer into a central artery is impracticable in humans; however, an appropriate correction of the results obtained in the V-A mode can be calculated if cardiac output, packed cell volume and substrate concentrations are determined (Layman \& Wolfe, 1987). Last, provided the same infusion sampling mode is always used, qualitative modifications observed in the same subjects in different situations remain valid.

Lipolysis can also be measured with ${ }^{13} \mathrm{C}$ or deuterium-labelled glycerol (Bougnères et al. 1982; Beylot et al. 1987b). The simultaneous determination of glycerol and FFA appearance rates brings out additional information. The only fate of glycerol released during lipolysis of stored TAG is its appearance in plasma, whereas some fatty acids can be re-esterified within the tissues without appearing in plasma (Fig. 1). This 'intracellular recycling' of fatty acids can be estimated by subtracting FFA appearance rate from three 
times the glycerol appearance rate. This approach has been used to demonstrate enhanced intracellular recycling in burn (Wolfe et al. 1987b) and hyperthyroid (Beylot et al. 1991) patients as well as in highly trained subjects (Romijn et al. 1993). The validity of this calculation of intracellular recycling requires that no glycerol is produced by another pathway such as glycolysis. De Freitas \& Depocas (1970) reported that glycerol could be produced in significant amounts by glycolysis in rats. However, Wolfe \& Peters (1987) carefully investigated this point in humans and provided convincing evidence that there was no significant production of glycerol from glycolysis in humans. It is also assumed, in the absence of appropriate data, the differences in tarnover rates between $\mathrm{V}-\mathrm{A}$ and $\mathrm{A}-\mathrm{V}$ modes, are comparable for glycerol and FFA and that their relative turnover rates (Ra glycerol:Ra FFA) is not sensitive to the infusion-sampling mode.

\section{Metabolic fate of non-esterified fatty acids}

The metabolic fate of FFA can also be determined, in part, with stable-isotope methodology. Briefly, plasma FFA taken up by tissues can either be oxidized or used for synthesis (TAG, cholesteryl ester or complex lipids). FFA oxidation can be estimated by measuring the appearance rate of ${ }^{13} \mathrm{CO}_{2}$ in expired gas during infusion of a ${ }^{13} \mathrm{C}$-labelled fatty acid (Wolfe et al. 1980). This oxidation represents, in the postabsorptive state, usually 30-50\% of FFA turnover rate (Bonadonna et al. 1990; Groop et al. 1991). The remaining FFA is considered to be re-esterified, a process one can call 'extracellular recycling' of plasma FFA (another definition of extracellular recycling was used by Wolfe et al. (1987b) who subtracted the total rate of lipid oxidation from plasma FFA turnover rate; since plasma FFA and total lipid oxidation are different, it seems more appropriate to use the former for the calculation). The significance of isotopic measurement of fatty acid oxidation has been questioned (Heiling et al. 1991) and some points need to be discussed. First, the position of the label in the fatty acid molecule has to be considered; for example, $\left[1-{ }^{13} \mathrm{C}\right]$ palmitate and $\left[2 \cdot{ }^{13} \mathrm{C}\right]$ palmitate catabolism will give respectively $\left[1-{ }^{13} \mathrm{C}\right]$ acetate and $\left[2-{ }^{13} \mathrm{C}\right]$ acetate. The metabolic fates of the label in $\left[1-{ }^{13} \mathrm{C}\right]-$ and $\left[2-{ }^{13} \mathrm{C}\right]$ acetate in Krebs cycle are different, giving different ${ }^{13} \mathrm{CO}_{2}$ production rates (Wolfe \& Jahoor, 1990) and this will result in different values of fatty acid oxidation rates. This probably explains why Clandini et al. (1988) found lower oxidation rates with $\left[16^{-13} \mathrm{C}\right]$ palmitate than with $\left[1-{ }^{13} \mathrm{C}\right]$ palmitate. Second, isotopic estimates of plasma FFA oxidation in the postabsorptive state are much lower (usually one-third to half) than estimates of lipid oxidation determined by indirect calorimetry (Bonadonna et al. 1990; Groop et al. 1991). Klein \& Wolfe (1987) suggested that part of this discrepancy could be related to the use in the calculation of arterial instead of venous palmitate enrichment. However, the discrepancy strongly suggests that fatty acids coming from plasma are diluted before oxidation by fatty acids originating from other sources, possibly intracellular TAG stores or, as shown in rats (Wolfe \& Durkot, 1985), circulating lipoproteinTAG. Moreover, in addition to dilution of the label, large intracellular fatty acid pools could result in a long delay between isotopic equilibrium of the tracer in plasma FFA pool and equilibration of ${ }^{13} \mathrm{CO}_{2}$ in expired gas (Heiling et al. 1991). Third, during prolonged tracer infusions some labelled fatty acid can be incorporated into tissues or circulating TAG. Subsequent release of labelled molecules from TAG in the intracellular fatty acid pool could lead to overestimation of plasma FFA oxidation. More methodological studies are needed to clarify these issues. We need convenient methods 


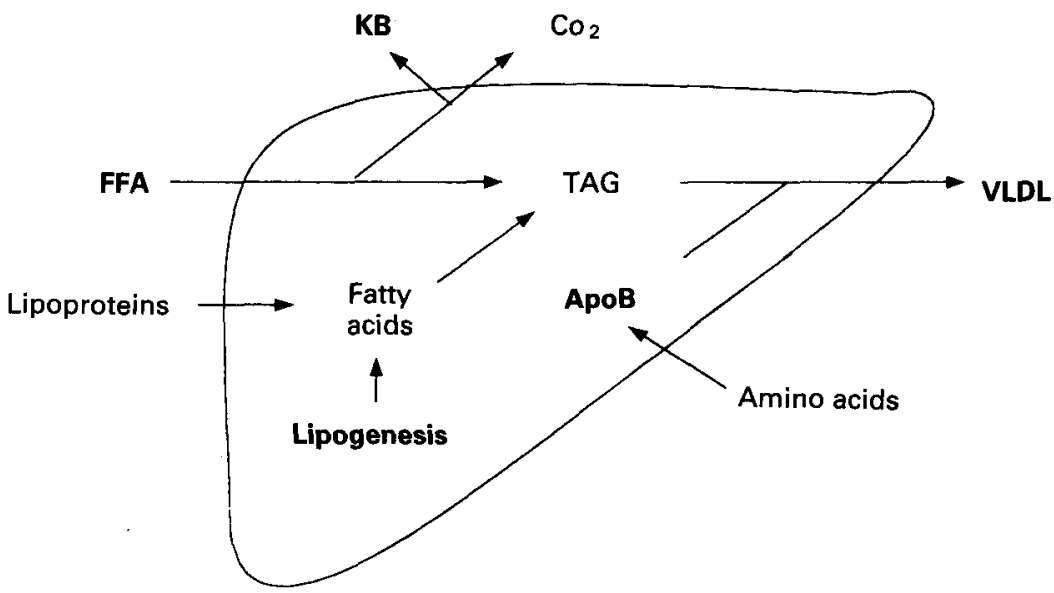

Fig. 2. Schematic representation of hepatic fatty acids and triacylglycerol metabolism. Kinetics for pathways and metabolites printed in bold can be measured using stable-isotope methodology. FFA, non-esterified fatty acids; TAG, triacylglycerol; VLDL, very-low-density lipoprotein; KB, ketone bodies.

of measuring the participation of tissues and circulating TAG in lipid oxidation. It would be very useful to be able to measure the in vivo enrichment of intracellular acyl-CoA, the true precursor pool for fatty acid oxidation, to improve determination of the relationship between plasma FFA and ${ }^{13} \mathrm{CO}_{2}$ enrichment.

Data on regional fatty acid metabolism can also be obtained. Arterio-venous differences can be combined with tracers to study muscular or adipose tissue fatty acid metabolism. Indirect information on hepatic lipid metabolism can also be collected. This is all the more important as liver is able to oxidize, synthesize and secrete lipids, and it plays a central role in lipoprotein metabolism. Plasma FFA taken up by liver can be oxidized completely to $\mathrm{CO}_{2}$ or incompletely to ketone bodies (KB), or re-incorporated into TAG or phospholipids before secretion in VLDL (Fig. 2). Simultaneous measurements of plasma FFA and KB kinetics facilitates the calculation of fatty acid conversion into KB (Beylot et al. 1987a): knowing the mean C-chain length of plasma FFA and assuming that all $\mathrm{KB}$ are derived from plasma FFA, it is possible to calculate the turnover rate of $\mathrm{KB}$ that would be achieved if the only fate of FFA was ketogenesis. Comparison with the actual $\mathrm{KB}$ appearance rate gives the percentage of FFA used for ketogenesis. The contribution of plasma FFA to TAG in VLDL can also be calculated by comparing the isotopic enrichment of, for example, palmitate in plasma FFA and in VLDL-TAG during infusion of labelled palmitate (Eaton et al. 1969). One possible limitation in such studies with stable-isotope-labelled tracers and conventional GLC-MS is a low enrichment level in VLDL-TAG due to dilution inside the liver by other sources of fatty acids. This limitation can be overcome by the use of GLC-combustion-isotoperatio MS (GLC-C-IRMS) which allows the measurement of very low enrichment levels (Goodman \& Brenna, 1992). In all these studies, one should keep in mind that the metabolic fate of fatty acids in liver depends, in part, on their C-chain length and degree of unsaturation (Hagenfeldt, 1975). Therefore, one should always be careful before extrapolating data obtained with one tracer to all fatty acids. 


\section{LIPOPROTEIN METABOLISM}

The last point brings us to the study of VLDL metabolism. Measuring the turnover rate of VLDL has long been a problem, using either stable or radioactive tracers; the incorporation of a labelled amino acid, usually leucine, in the main apoprotein of VLDL, apoprotein B (Halliday et al. 1993) provides a solution. Knowing the initial rate of incorporation of the label into apoprotein B and the intrahepatic isotopic enrichment of leucine (the latter calculated from plasma $\alpha$-ketoisocaproate or leucine apoprotein $B$ enrichment at plateau) one can calculate the fractional secretion rate of apoprotein $B$ and, using its concentration and distribution volume, the absolute secretion rate (in steady-state situations). If we know the respective concentrations of VLDL-TAG and apoprotein $\mathrm{B}$, it is then possible to estimate the secretion rate of VLDL-TAG. This method can also be used to measure the secretion rates of apoprotein $A$ and the transfer of apoprotein B from VLDL to LDL.

The source of fatty acids used in the synthesis of VLDL-TAG (plasma FFA, hepatic lipogenesis, recycling of the fatty acids of lipoproteins taken up and degraded by liver; Fig. 2) can be determined in part. As well as re-esterification of plasma FFA, we can estimate the contribution of hepatic lipogenesis. Two methods using stable isotopes have been devised. The first uses the infusion of ${ }^{13} \mathrm{C}$-labelled acetate and the measurement of excess ${ }^{13} \mathrm{C}$ appearing in palmitate or stearate VLDL-TAG (Hellerstein et al. 1991a). The calculation requires a knowledge of liver cytosolic acetyl-CoA isotopic enrichment. This can be achieved by 'chemical biopsy' using sulphamethoxazole to sample the acetyl-CoA pool (Hellerstein et al. 1991a). Initially the ${ }^{13} \mathrm{C}$ excess in acetylated sulphamethoxazole was measured with HPLC-MS, but recently a GLC-MS method has been proposed (Zhang et al. 1993). Another very elegant way of measuring cytosolic acetyl-CoA enrichment is the mass isotopomer distribution analysis (MIDA) developed by Hellerstein et al. (1991b) and Kharroubi et al. (1992); the relative proportion of palmitate molecules labelled with zero, one, two, . . . eight excess ${ }^{13} \mathrm{C}$ is a direct function of the enrichment of acetyl-CoA. Thus, measuring the distribution of the various isotopomers of palmitate facilitates the determination of acetyl-CoA enrichment and, thus, the contribution of lipogenesis to fatty acids in VLDL-TAG. However, this method requires high precision in the measurement of isotopomer distribution. The second method takes advantage of the incorporation of deuterium during lipogenesis, after enrichment of total body water with ${ }^{2} \mathrm{H}_{2} \mathrm{O}$, and dates back to the classic work of Rittenberg \& Schoenheimer (1937). However, it is necessary to attain relatively high enrichment in water in order to obtain deuterium enrichments of fatty acids measurable with GLC-MS. The development of isotope-ratio MS measuring low deuterium enrichment permits the use of this method in ethical conditions in humans, at the expense of rather tedious sample processing (Leitch \& Jones, 1993). Studies using these two methods conclude that lipogenesis is a minor contributor (less than 10-15\%) to VLDL-TAG-fatty acids, but there are significant differences between results obtained with $\left[{ }^{13} \mathrm{C}\right]$ acetate $(1-4 \%)$ and ${ }^{2} \mathrm{H}_{2} \mathrm{O}(5-15 \%)$. More experimental validations and perhaps more appropriate modelling should be performed before these methods are used for studies of nutritional or hormonal regulation of hepatic lipogenesis in humans. These two methods can also be used to measure the synthesis of cholesterol (Jones \& Schoeller, 1990; Neese et al. 1993).

It would be useful also to be able to measure the contribution to VLDL-TAG of fatty acids cycling back from lipoprotein taken up and degraded by liver. This would necessitate the infusion of specific lipoproteins previously labelled on the fatty acid part 
of their TAG. This procedure has been used with radioactive isotopes (Wolfe et al. 1973) to measure the turnover rate of lipoproteins and to study some aspects of the metabolic fate of their various lipid fractions (Wolfe et al. 1985). It would be useful also for the determination of the contribution of VLDL-fatty acids to total lipid oxidation, as previously discussed. However, use of this procedure in humans raises serious ethical concerns and it should be restricted to animal studies.

\section{METABOLISM OF EXOGENOUS FAT}

An important topic in metabolic studies is the disposal of exogenous nutrients. In addition to diagnosis of fat malabsorption and maldigestion (Watkins et al. 1982; Vantrapen et al. 1989) ${ }^{2} \mathrm{H}$ - or ${ }^{13} \mathrm{C}$-labelled TAG can be used to investigate the metabolic fate of orally ingested or intravenously infused lipids. For example, deuterium-labelled TAG have been used to determine the contribution of dietary fatty acids to milk lipids in normal lactating women (Hachey et al. 1987; Emken et al. 1989). Measurement of ${ }^{13} \mathrm{CO}_{2}$ excretion rate in expired gas after ingestion of a ${ }^{13} \mathrm{C}$-labelled-TAG load facilitates the calculation of the oxidation of exogenous fat and, thus, the respective roles of oxidative and non-oxidative pathways in its disposal (Metges \& Wolfram, 1991). Also, the contribution of endogenous and exogenous lipids to total lipid oxidation can be calculated by the simultaneous use of indirect calorimetry. These procedures have confirmed that medium-chain TAG are more readily oxidized in humans than long-chain TAG (Watkins et al. 1982; Metges \& Wolfram, 1991). Moreover, ${ }^{13} \mathrm{C}$-labelled triolein is more rapidly oxidized than $\left[{ }^{13} \mathrm{C}\right]$ tripalmitin (Watkins et al. 1982). Therefore, in addition to C-chain length, it appears that degree of unsaturation influences the metabolic fate of orally ingested fatty acids. For better understanding of the direction of the metabolism of exogenous fat, toward or away from oxidation, it would be important to trace the pathways followed by labelled fatty acids between intestinal absorption and utilization by tissues. Combining the separation of the different lipoproteins and the different lipid fractions with the sensitivity of detection of excess ${ }^{13} \mathrm{C}$ by GLC-IRMS, provides a promising tool for achieving this aim.

This methodology will also be useful for studying the metabolism of essential fatty acids and long-chain polyunsaturated fatty acids (arachidonic acid, eicosapentaenoic and docosahexaenoic acid) and their use for synthesis of important bioactive molecules such as prostaglandins. Appropriate tracers are available through lipid synthesis by algae grown in ${ }^{13} \mathrm{CO}_{2}$-enriched atmosphere (Goodman \& Brenna, 1992). Therefore, it should be possible to follow their incorporation into the various lipoproteins and, at least, into the lipid fraction of circulating cells. Such investigations would be important given previous studies showing the profound impact of very-long-chain $n-3$ fatty acids on lipid and carbohydrate metabolism (Fasching et al. 1991; Storlien et al. 1991; Rustan et al. 1993).

\section{CONCLUSION}

Significant advances in the area of the exploration of fat metabolism with stable isotopes and MS techniques have been achieved in recent years. GLC-IRMS should allow further progress. However, several aspects, especially the role of tissues and circulating TAG in total lipid oxidation remain difficult to explore in humans. 


\section{REFERENCES}

Beylot, M., Beaufrère, B. \& Riou, J. P. (1987a). Effect of epinephrine on the relationship between non esterified fatty acid availability and ketone body production in post-absorptive man: evidence for a hepatic antiketogenic effect of epinephrine. Journal of Clinical Endocrinology and Metabolism 65, 914-921.

Beylot, M., Martin, C., Beaufrère, B., Riou, J. P. \& Mornex, R. (1987b). Determination of steady-state and non steady-state glycerol kinetics in humans using deuterium labeled tracer. Journal of Lipid Research 28, 414-422.

Beylot, M., Martin, C., Laville, M., Riou, J. P., Cohen, R. \& Mornex, R. (1991). Lipolytic and ketogenic fluxes in human hyperthyroidism. Journal of Clinical Endocrinology and Metabolism 73, 42-49.

Bonadonna, R. C., Groop, L. C., Zych, K., Shank, M. \& De Fronzo, R. A. (1990). Dose-dependent effect of insulin on plasma free fatty acid turnover and oxidation in humans. American Journal of Physiology 259, E736-E750.

Bougnères, P. F. \& Bier, D. M. (1982). Stable isotope dilution method for measurement of palmitate content and labeled palmitate tracer enrichment in microliter plasma samples. Journal of Lipid Research 23, $502-507$.

Bougnères, P. F., Karl, I. E., Hillman, L. S. \& Bier, D. M. (1982). Lipid transport in the human newborn. Palmitate and glycerol turnover and the contribution to neonatal hepatic glucose output. Journal of Clinical Investigation 70, 268-276.

Cahill, G. F. (1976). Starvation in man. Journal of Clinical Endocrinology and Metabolism 5, 397-415.

Clandini, M. T., Kheterpol, S., Kielo, E. S., Franck, M. H., Tokarsko, B. \& Goh, Y. K. (1988). Chain shortening of palmitic acid in human subjects. American Journal of Clinical Nutrition 48, 587-591.

De Freitas, A. S. W. \& Depocas, F. (1970). Glyceride-glycerol release and the interconversion of glucose and glycerol in normal and fasted rats. Canadian Journal of Physiology and Pharmacology 48, 561-568.

Eaton, R. P., Berman, M. \& Steinberg, D. (1969). Kinetic studies of plasma free fatty and acid triglyceride metabolism in man. Journal of Clinical Investigation 48, 1560-1579.

Emken, E. A., Arlof, R. O., Hachey, D. L., Garza, C., Thomas, M. R. \& Brown-Booth, L. (1989). Incorporation of deuterium labeled fatty acids into human milk, plasma, and lipoprotein phospholipids and cholesteryl esters. Journal of Lipid Research 30, 395-402.

Fasching, P., Ratheiser, K., Waldhausl, W., Romac, M., Osterrude, W., Nowotny, P. \& Vierhapper, M. (1991). Metabolic effects of fish oil supplementation in patients with impaired glucose tolerance. Diabetes 40, 538-589.

Goodenough, R. A. \& Wolfe, R. R. (1983). A model for isotopic sampling and administration in constant infusion experiments: a test with ${ }^{13} \mathrm{C}$ palmitate. American Journal of Clinical Nutrition 37, 1004-1009.

Goodman, K. J. \& Brenna, J. Th. (1992). High sensitivity tracer detection using high precision gas chromatography-combustion isotope ratio mass spectrometry and highly enriched [U-13 C] labeled precursors. Analytical Chemistry 64, 1088-1095.

Gordon, G. W. (1980). Complex lipids. In Biochemical Applications of Mass Spectrometry, 1st supplementary vol., pp. 173-209 [G. R. Waller and O. C. Dermer, editors]. New York, Chichester, Brisbane, Toronto: J. Wiley and Sons.

Groop, L. C., Bonadonna, R. C., Shank, M., Petrimes, S. \& De Fronzo, R. P. (1991). Role of free fatty acids and insulin in determining free fatty acid and lipid oxidation in man. Journal of Clinical Investigation 87, 83-89.

Hachey, D. L., Thomas, M. R., Emken, E. A., Garza, C., Brown-Booth, L., Dalof, R. O. \& Klein, P. A. (1987). Human lactation: maternal transfer of dietary triglycerides labeled with stable isotopes. Journal of Lipid Research 28, 1185-1192.

Hagenfeldt, L. (1975). Turnover of individual free fatty acids in man. Federation Proceedings 34, 2246-2249.

Halliday, D., Venkatesan, S. \& Pacy, P. (1993). Apolipoprotein metabolism: a stable-isotope approach. American Journal of Clinical Nutrition 57, Suppl., 7265-7315.

Heiling, V. J., Miles, J. M. \& Jensen, M. D. (1991). How valid are isotopic measurements of fatty acid oxidation? American Journal of Physiology 261, E572-E577.

Hellerstein, M. K., Christiansen, A., Kaempfer, S., Kletke, C., Wu, H., Reio, J. S., Mulligan, K., Hellerstein, N. S. \& Shackleton, C. H. L. (1991a). Measurement of de novo hepatic lipogenesis in humans using stable isotopes. Journal of Clinical Investigation 87, 1841-1852.

Hellerstein, M. K., Kletke, C., Kaempfer, S., Wu, K. \& Shackleton, C. H. L. (1991b). Use of mass isotopomer distributions in secreted lipids to sample lipogenic acetyl $\mathrm{CoA}$ pool in humans. American Journal of Physiology 261, E479-E486.

Jones, P. J. H. \& Schoeller, D. A. (1990). Evidence for diurnal periodicity in human cholesterol synthesis. Journal of Lipid Research 31, 667-673. 
Kharroubi, A. T., Masterson, T. M., Aloaghlas, T. A., Kennedy, K. A. \& Kellemer, J. K. (1992). Isotopomer spectral analysis of triglyceride fatty acid synthesis in 3T3 cells. American Journal of Physiology 263, E667-E675.

Klein, S. \& Wolfe, R. (1987). The use of isotopic tracers in studying lipid metabolism in human subjects. In Baillière's Clinical Endocrinology and Metabolism, pp. 797-816. London: Baillière Tindall.

Layman, D. K. \& Wolfe, R. R. (1987). Sample site relation for tracer studies applying a undirectional circulatory approach. American Journal of Physiology 253, E173-E178.

Leitch, C. \& Jones, P. J. H. (1993). Measurement of human lipogenesis using deuterium incorporation. Journal of Lipid Research 34, 157-163.

Metges, C. C. \& Wolfram, G. (1991). Medium and long chain triglycerides labeled with ${ }^{13}$ C: a comparison of oxidation after oral or parenteral administration in humans. Journal of Nutrition 121, 31-36.

Miles, J. M., Ellman, M. G., McLean, K. L. \& Jensen, M. A. (1987). Validation of a new method for determination of free fatty acid turnover. American Journal of Physiology 252, E431-E438.

Murphy, R. C. (1993). Mass spectrometry of lipids. In Handbook of Lipid Research, vol. 7 [F. Snyder, editor]. New York and London: Plenum Press.

Neese, R. A., Faix, D., Kletke, C., Wu, K., Wang, A. C., Shackleton, C. H. L. \& Hellerstein, M. K. (1993). Measurement of endogenous synthesis of plasma cholesterol in rats and humans using MIDA. American Journal of Physiology 264, E136-E147.

Rittenberg, D. \& Schoenheimer, B. (1937). Deuterium as an indicator in the study of intermediary metabolism. XI. Further studies on the biological uptake of deuterium into organic substances with special references to fat and cholesterol formation. Journal of Biological Chemistry 121, 235-253.

Romijn, J. A., Klein, S., Coyle, E. F., Sidossis, L. S. \& Wolfe, R. R. (1993). Strenuous endurance training increases lipolysis and triglyceride fatty acid cycling at rest. Journal of Applied Physiology 75, 108-113.

Rustan, A. C., Hustvedt, B. E. \& Drevon, C. A. (1993). Dietary supplementation of very long chain A-3 fatty acids decreases whole body lipid utilization in the rat. Journal of Lipid Research 34, 1299-1309.

Sacca, L., Toffolo, G. \& Cobelli, C. (1992). Va-A and A-V modes in whole body and regional kinetics: domain of validity from a physiological model. American Journal of Physiology 263, E597-E606.

Spitzer, J. J. (1975). Application of tracers in studying free fatty acid metabolism of various organs in vivo. Federation Proceedings 34, 2242-2245.

Storlien, L. H., Jenkins, A. B., Chisholm, D. J., Pascoe, W. S., Khouri, S. \& Kraegen, E. W. (1991). Influence of dietary fat composition on development of influence resistance in rats. Diabetes 40, 280-289.

Vantrapen, G. R., Rutgeerts, J., Ghoos, Y. F. \& Ihele, M. J. (1989). Mixed triglyceride breath test: a non invasive test of pancreatic lipase activity in the duodenum. Gastroenterology 96, 1126-1134.

Watkins, J. B., Klein, P. D., Schoeller, D. A., Kirscher, B. S., Park, R. \& Perman, J. A. (1982). Diagnosis and differentiation of fat malabsorption in children using ${ }^{13} \mathrm{C}$ labeled lipids: trioctanoin, triolein and palmitic acid breath test. Gastroenterology 82, 911-917.

Wolfe, B. M., Kane, J. P., Havel, R. J. \& Brewster, M. P. (1973). Mechanism of the hypolipemic effect of clofibrate in post-absorptive man. Journal of Clinical Investigation 52, 2146-2159.

Wolfe, R. R. \& Durkot, M. J. (1985). Role of VLDL in the energy metabolism of the rat. Journal of Lipid Research 26, 210-217.

Wolfe, R. R., Evans, J. E. \& Mullany, C. J. (1980). Measurement of plasma free fatty acid turnover and oxidation using $\left[1-{ }^{13} \mathrm{C}\right]$ palmitic acid. Biomedical Mass Spectrometry 7, 168-171.

Wolfe, R. R., Hernoon, D. N., Jahoor, F., Miyoshi, H. \& Wolfe, M. (1987b). Effect of severe burn injury on substrate cycling by glucose and fatty acids. New England Journal of Medicine 317, 403-408.

Wolfe, R. R. \& Jahoor, F. (1990). Recovery of labeled $\mathrm{CO}_{2}$ during the infusion of C-1 vs C-2 labeled acetate: implications of tracer studies of substrate oxidation. American Journal of Clinical Nutrition 51, 248-252.

Wolfe, R. R. \& Peters, E. J. (1987). Lipolytic response to glucose infusion in human subjects. American Journal of Physiology 252, E218-E223.

Wolfe, R. R., Peters, E. J., Klein, S., Holland, O. B., Rosenblatt, J. \& Garry, H. J. (1987a). Effect of short term fasting on lipolytic responsiveness in normal and obese human subjects. American Journal of Physiology 252, E189-E196.

Wolfe, R. R., Shaw, J. H. F. \& Durkot, M. J. (1985). Effect of sepsis on VLDL kinetics: responses in basal state and during infusion. American Journal of Physiology 248, E732-E740.

Zhang, Y., Agarwal, K. C., Beylot, M., Soloviev, M. V., David, F., Reider, M., Tserng, K. Y. \& Brunengraber, H. (1993). Assay of the acetyl CoA probe acetyl-sulfamethoxazole and of sulfamethoxazole by gas chromatography-mass spectrometry. Analytical Biochemistry 212, 481-486. 